Check for updates

Cite this: RSC Adv., 2017, 7, 19296

\section{Study on the performance of micro-flow injection preconcentration method on-line coupled to thermospray flame furnace AAS using MWCNTs wrapped with polyvinylpyridine nanocomposites as adsorbent}

\author{
César Ricardo Teixeira Tarley, (D) *ab Kristiany Moreira Diniz, ${ }^{a}$ Fabio Antonio Cajamarca \\ Suquila and Mariana Gava Segatelli ${ }^{a}$
}

\begin{abstract}
This work describes the synthesis and characterization of a new adsorbent nanocomposite based on multiwalled carbon nanotubes (MWCNTs) and polyvinylpyridine and its use in the development of a highly sensitive micro-flow injection preconcentration method coupled to TS-FF-AAS for the determination of very low levels of $\mathrm{Cd}$. The characterization of the nanocomposite was performed by FT-IR, TGA, SEM, TEM and textural data measurements using the BET and BJH methods. The optimized conditions of the micro-flow injection preconcentration method involved a preconcentrated sample $(8.8 \mathrm{~mL})$ at $\mathrm{pH} 8.0$ flowed through $50.0 \mathrm{mg}$ of nanocomposite packed into a mini-column at a flow rate of $4.4 \mathrm{~mL} \mathrm{~min}^{-1}$. The on-line elution of $\mathrm{Cd}(I)$ ions towards the TS-FF-AAS detector was carried out in countercurrent at a flow rate of $0.6 \mathrm{~mL} \mathrm{~min}{ }^{-1}$ using $1.0 \mathrm{~mol} \mathrm{~L}^{-1} \mathrm{HCl}$. The analytical curve ranged from 0.12 to $6.0 \mu \mathrm{g} \mathrm{L}^{-1}(r$ $=0.997$ ), and an enhancement factor of 19.5 , sample throughput of $15 \mathrm{~h}^{-1}$ and consumptive index of $0.45 \mathrm{~mL}$ were achieved. In terms of sensitivity, the uniquely high adsorption capacity of the nanocomposite was confirmed by the low limit of detection $\left(36 \mathrm{ng} \mathrm{L}^{-1}\right)$ achieved after implementing the preconcentration step in TS-FF-AAS. In terms of selectivity, the proposed method was shown to be tolerable to several foreign ions and applicable to different kinds of waters (tap, mineral, lake, and synthetic seawater), cigarettes, a food sample (powder chocolate), a medicinal herb (Ginkgo biloba) and a certified reference material (fish protein DORM-3).
\end{abstract}

Received 28th January 2017 Accepted 13th March 2017

DOI: 10.1039/c7ra01220a

rsc.li/rsc-advances medicinal herbs such as Gingko biloba as well as chocolate, mainly chocolate rich in cocoa, might be a significant source of Cd ingestion. ${ }^{7,8}$ Thus, the determination of $\mathrm{Cd}$ in different kinds of samples is of particular interest for quality control and environmental monitoring. However, due to the very low Cd content along with the differences between matrices in the samples, the development of reliable methods capable of directly analyzing Cd in different kinds of samples is usually a difficult task. ${ }^{9}$ Hence, the pretreatment of samples using preconcentration methods is highly recommended for reliable analysis, especially if one considers the use of analytical techniques with high sensitivity, such as flame atomic absorption spectrometry (FAAS). ${ }^{\mathbf{1 0}-\mathbf{1 2}}$

Among the preconcentration methods including solid phase extraction (SPE), co-precipitation and micro liquid-liquid extraction, the first is still the most used method for metal ion extraction and is mainly used in combination with atomic spectrometric techniques. ${ }^{\mathbf{1 3 , 1 4}}$ The advantages of SPE stem from its simplicity to perform on-line or off-line, high preconcentration factor and flexibility due to the availability of commercial adsorbents such as octadecyl- $\mathrm{C}_{18}-$ silica, Amberlite XAD-2, 
polyurethane foam, Amberlyst 36, Amberlite XAD-16, Chromosorb-106. ${ }^{15}$

Although widely used, these adsorbents suffer from some drawbacks, such as lack of selectivity, the need to use auxiliary chelating agents, low chemical stability in a large $\mathrm{pH}$ range, swelling effect in different fluids, low regeneration ability and the need for toxic organic solvents as eluents in the preconcentration system. ${ }^{16-18}$ Therefore, many efforts in the field of separation science have been made to synthesize new adsorbent materials with better adsorptive and selective features towards metal ion adsorption. Carbonaceous nanoadsorbent materials, including carbon nanotubes, ${ }^{19}$ carbon black ${ }^{20}$ and graphene; ${ }^{21}$ metal-organic frameworks (MOFs); ${ }^{22}$ nanostructured ionimprinted polymers (IIPs); ${ }^{23}$ inorganic nanoadsorbents; ${ }^{24}$ nanostructured mixed oxides; $;^{25}$ magnetic adsorbents; ${ }^{26}$ and nanocomposites based on nanocarbonaceous materials and polymers ${ }^{27}$ represent a class of materials that has been widely investigated for metal ion adsorption. The basic advantage of these nanoadsorbents is that most of the binding sites responsible for the high chemical activity and adsorption capacity towards metal ions are on the surface of the nanomaterial. ${ }^{25}$

Carbon nanotubes (CNTs) are one class of carbonaceous nanoadsorbent materials that is currently considered the most exploited for metal ion adsorption; however, the adsorption properties of these materials depend upon their functional groups, dispersibility in aqueous media, site density and surface area. ${ }^{27}$ From this perspective, nanocomposite materials based on CNTs and chelating polymers are promising for solving these drawbacks by improving the dispersion of the carbonaceous phase and enhancing the ratio of polymer binding sites to volume due to the nanoscale polymers synthetized on the surface of the carbonaceous phase. ${ }^{28,29}$ Furthermore, the preparation of CNT/polymer nanocomposites may overcome the poor accessibility of the analyte to the binding sites of the polymer and the slow dynamic adsorption compared to bulk polymer. ${ }^{30}$

Although very interesting, the studies dedicated to combining CNTs and polymers have been performed mostly to improve the mechanical strength of the polymer in the nanocomposite $;^{31}$ few have examined metal adsorption. To the best of our knowledge, the few studies reported on this subject involve the use of CNT/polyaniline (PANI) and poly(3,4dioxythiophene) (PEDOT) nanocomposites for Au adsorption, ${ }^{32}$ CNT/PAMAN for Ni, Zn, As and Co adsorption, ${ }^{27} \mathrm{CNT} /$ poly(2-amino thiophenol) for $\mathrm{Cd}$ and $\mathrm{Pb}$ adsorption, ${ }^{33}$ and $\mathrm{CNT} /$ polypyrrole for $\mathrm{Pb}, \mathrm{Ni}$, and $\mathrm{Cd}$ adsorption..$^{28}$ Additionally, one should note that no preconcentration studies have been reported from the analytical point of view on the assessment of the performance of CNT/polymer composites as adsorbents for $\mathrm{Cd}$ ions using micro-flow injection as a preconcentration method.

Therefore, in this study, we have developed a CNT/ polyvinylpyridine nanocomposite for the preconcentration of Cd using a micro-flow injection method on-line coupled to thermospray FAAS (TS-FF-AAS). Polyvinylpyridine was chosen as the chelating polymer due to the presence of nitrogen in the pyridine ring, which has a strong ability to bind $\mathrm{Cd}$ ion. ${ }^{34}$ Moreover, apart from its intrinsic sensibility for volatile metal ions, the interest in the on-line coupling of the preconcentration method with TS-FF-AAS results from its low flow rate. Therefore, micro-column packed with CNT/polyvinylpyridine nanocomposite seems to be very interesting for operating at low flow rates.

The nanocomposite was characterized by FTIR, TGA, SEM, TEM and textural data measurements using the BET and BJH methods, and the analytical performance of the proposed method for real analysis was checked by the analysis of different kinds of samples (water, chocolate, medicinal herbs, and cigarettes) and a certified reference material (fish protein DORM-3).

\section{Experimental}

\subsection{Apparatus}

Absorption measurements were performed using a Shimadzu AA-7000 flame atomic absorption spectrometer (Kyoto, Japan) equipped with a hollow cathode lamp for $\mathrm{Cd}$ and a deuterium lamp for background correction. The hollow cathode lamp was operated at $8.0 \mathrm{~mA}$, and the wavelength was set at $229.0 \mathrm{~nm}$. The flame composition was operated with an acetylene flow rate of 2.0 $\mathrm{L} \mathrm{min}^{-1}$ and an airflow rate of $10.0 \mathrm{~L} \mathrm{~min}^{-1}$. The flow adsorbent preconcentration system was constructed using a peristaltic pump (Gilson Minipuls evolution; Middleton, USA) furnished with Tygon ${ }^{\circledR}$ tubes to propel all samples and reagent solutions. A homemade minicolumn made of polyethylene (3.0 $\mathrm{cm}$ in length and $0.5 \mathrm{~cm}$ in internal diameter at the top) packed with $50.0 \mathrm{mg}$ of nanocomposite was coupled to a homemade injector commutator for preconcentration and elution procedures. A piece of cotton was fixed at the extremities of the minicolumn by inserting the upper end of a conical tip into the minicolumn cylindrical edge to avoid the loss of material. The TS-FF-AAS apparatus included a ceramic capillary $(10 \mathrm{~cm})$ nickel tube made of non-porous $\mathrm{Al}_{2} \mathrm{O}_{3}$ ceramic (Friatec, Mannhein, Germany) and a nickel tube (Inconel 600 tube with $72 \% \mathrm{Ni}, 14-17 \% \mathrm{Cr}, 6-10 \% \mathrm{Fe}, 0.15 \% \mathrm{C}, 1 \% \mathrm{Mn}$, and $0.5 \% \mathrm{SI}$; Camacam, Brazil) with a length of $10 \mathrm{~cm}$ and an i.d. of $1.0 \mathrm{~cm}$ and containing six holes with i.d. $=2.5 \mathrm{~mm}$. Scanning electron microscopy (SEM) analyses were performed using a Model Quanta 200-Philips-FEI microscope (Amsterdam, Netherlands), and the samples were coated with a thin layer of carbon to minimize charging under the incident electron beam. For transmission electron microscopy (TEM), a JEOL ${ }^{\circledR}$ JEM-1400 microscope with an accelerating voltage of $120 \mathrm{kV}$ was used. For TEM sample treatment, the material was dispersed in ethanol by sonication for $20 \mathrm{~min}$, and the suspension was dried under vacuum on copper grids.

A Shimadzu FTIR 8300 spectrometer (Kyoto, Japan) operating in transmission mode between 4000 and $400 \mathrm{~cm}^{-1}$ was used to elucidate the functional groups present in the nanocomposites. The surface area and average pore diameter were obtained by the multipoint BET and BJH methods, respectively, based on nitrogen adsorption experiments using a physical adsorption method with a Quantachrome Model Nova 1200e automatic nitrogen gas adsorption instrument (Boynton Beach, 
FL, USA). Thermogravimetric analysis (TGA) was carried using a 4000 Perkin Elmer thermobalance (Waltham, USA). For TGA analysis, $\sim 10 \mathrm{mg}$ of sample was heated from $30{ }^{\circ} \mathrm{C}$ to $900{ }^{\circ} \mathrm{C}$ at a rate of $10{ }^{\circ} \mathrm{C} \mathrm{min}^{-1}$ under a nitrogen flow of $20 \mathrm{~mL} \mathrm{~min}{ }^{-1}$. The digestion of a certified reference material and cigarette samples was carried out using a microwave laboratory system (Microwave Milestone).

\subsection{Reagents}

All reagents were of analytical grade. All solutions and their respective dilutions were prepared with water purified using a Millipore Milli-Q purification system (Bedford, MA, USA). Before use, all glassware was kept for $24 \mathrm{~h}$ in a bath of $\mathrm{HNO}_{3}$ $(10 \% \mathrm{v} / \mathrm{v})$ to avoid metal contamination. The reagents and solvents used in the synthesis were trimethylolpropane trimethacrylate (TRIM) (99.9\%), 2,20-azoisobutyronitrile (AIBN) (98\%), vinyltrimethoxysilane (VTMS) ( $\geq 97.5 \%)$, toluene (HPLC grade; $\geq 99.9 \%$ ), dimethylformamide (DMF; $\geq 99.8 \%$ ), and hydroquinone $(\geq 99 \%)$, all acquired from Sigma-Aldrich (Steinheim, Germany). MWCNTs were supplied by CNTs Co. Ltd. Yeonsu-Gu, Incheon, Korea (93\%, diameter $=10-40 \mathrm{~nm}$; length $=5-20 \mu \mathrm{m}$ ). Buffer solutions (phosphate, Tris-HCl, ammoniacal and borate; Merck, Massachusetts, USA) were used without further purification. The desired $\mathrm{pH}$ was adjusted with sodium hydroxide or hydrochloric acid solutions. A standard Cd(II) solution $\left(5.0 \mu \mathrm{g} \mathrm{L}^{-1}\right)$ was prepared from a standard Cd(II) solution (1000.0 mg L ${ }^{-1}$; Spec sol, Jacareí, São Paulo, Brazil) using appropriate dilutions. Standard solutions of $\mathrm{Co}(\mathrm{II}), \mathrm{Cu}(\mathrm{II})$, $\mathrm{Fe}(\mathrm{III}), \mathrm{Pb}$ (II), $\mathrm{Mn}$ (II), $\mathrm{Zn}$ (II), and Ca(II) used in interference studies were prepared daily by the appropriate dilution of stock solutions containing $1000 \mathrm{mg} \mathrm{\textrm {L } ^ { - 1 }}$ (Vetec and Specsol, Brazil). Humic acid powder was acquired from Sigma-Aldrich and dissolved in $1.0 \mathrm{~mol} \mathrm{~L}^{-1} \mathrm{KOH}$ solution. The acids, bases and salts $\left(\mathrm{HNO}_{3}, \mathrm{NaOH}, \mathrm{NH}_{4} \mathrm{OH}, \mathrm{H}_{2} \mathrm{O}_{2}\right.$ and $\left.\mathrm{KCl}\right)$ were obtained from Sigma-Aldrich and used without further purification.

\subsection{Synthesis of MWCNT-polyvinylpyridine nanocomposites}

To create hydroxyl groups on the MWCNT surface capable of reacting with vinyltriethoxysilane, MWCNTs were oxidized according to the literature with minor modifications. ${ }^{\mathbf{1 1}}$ For this task, $1000 \mathrm{mg}$ of MWCNT were mixed with $133.3 \mathrm{~mL}$ of a $\mathrm{HNO}_{3} /$ $\mathrm{H}_{2} \mathrm{SO}_{4}(3: 1, \mathrm{v} / \mathrm{v})$ mixture and refluxed at $65{ }^{\circ} \mathrm{C}$ for $2 \mathrm{~h}$. Afterwards, the oxidized MWCNTs were successively washed with deionized water ( $\mathrm{pH} 7.0$ ) to remove acid excess, dried at $60{ }^{\circ} \mathrm{C}$ and stored at room temperature. Subsequently, $500.0 \mathrm{mg}$ of oxidized MWCNTs were dispersed in $40.0 \mathrm{~mL}$ of toluene in a three-neck, round-bottom flask and kept in an ultrasonic bath (40 kHz) for $20 \mathrm{~min}$. Then, $12.4 \mathrm{~g}$ of vinyltrimethoxysilane previously dissolved in $67.0 \mathrm{~mL}$ of toluene containing $0.12 \mathrm{~g}$ of hydroquinone was slowly added to the mixture under stirring. One of the three necks was sealed, the central neck was coupled to a reflux condenser, and the other neck was purged with nitrogen $\left(\mathrm{N}_{2}\right)$ for $10 \mathrm{~min}$. Afterwards, the neck was sealed, and the mixture was heated at $100{ }^{\circ} \mathrm{C}$ in an oil bath for $6 \mathrm{~h}$ under reflux. The obtained functionalized MWCNTs were washed with ethanol and dried at $50{ }^{\circ} \mathrm{C}$ for $6 \mathrm{~h}$. For the synthesis of nanocomposite, $40.0 \mathrm{mg}$ of functionalized MWCNTs were dispersed in $15.0 \mathrm{~mL}$ of DMF in a flat-bottomed flask and kept in an ultrasonic bath $(40 \mathrm{kHz})$ for $20 \mathrm{~min}$. In the next step, $800 \mu \mathrm{L}$ of the functional monomer 4-vinylpyridine $(7.42 \mathrm{mmol}), 800 \mu \mathrm{L}$ of crosslinking agent (TRIM; $2.51 \mathrm{mmol}$ ) and $80.0 \mathrm{mg}$ of the radical initiator (AIBN; $0.48 \mathrm{mmol}$ ) were added to the mixture. The mixture was transferred to a round-bottom flask, purged with $\mathrm{N}_{2}$ for $10 \mathrm{~min}$, sealed, and heated at $60{ }^{\circ} \mathrm{C}$ for $24 \mathrm{~h}$ under constant stirring. After synthesis, the final material was removed from the flask, rinsed with Milli-Q water to remove excess reagent, and dried at $50{ }^{\circ} \mathrm{C}$ for 24 h. Fig. 1 shows a schematic representation of the synthesis of MWCNT and polyvinylpyridine nanocomposites.

\subsection{System of preconcentration for $\mathrm{Cd}$ (II) on-line coupled to TS-FF-AAS}

The on-line preconcentration system was based on loading 8.8 $\mathrm{mL}$ of sample buffered with $0.01 \mathrm{~mol} \mathrm{~L}^{-1}$ ammoniacal buffer (pH 8.0) through $50.0 \mathrm{mg}$ of MWCNT-polyvinylpyridine nanocomposite packed into a mini-column $(3.0 \mathrm{~cm}$ in length and $0.5 \mathrm{~cm}$ in upper internal diameter) made of polyethylene at a flow rate of $4.4 \mathrm{~mL} \mathrm{~min}^{-1}$ (Fig. 2). To build the homemade cylindrical mini-column, a small piece of cotton tissue was placed at each end of the mini-column to hold the nanocomposite. The pieces of cotton tissue were fixed at the extremities of the mini-column by inserting the upper end of a conical tip into the mini-column cylindrical edge. The on-line elution step was coupled to the TS-FF-AAS detector and performed in countercurrent at a flow rate of $0.6 \mathrm{~mL} \mathrm{~min}^{-1}$ using $1.0 \mathrm{~mol} \mathrm{~L}^{-1} \mathrm{HCl}$.

\subsection{Sample preparation}

Tap and mineral waters were acquired from the Campus of State University of Londrina and a local supermarket, respectively. After sampling, the $\mathrm{pH}$ of the sample was adjusted to 8.0 with $0.01 \mathrm{~mol} \mathrm{~L}^{-1}$ ammoniacal buffer, and the sample was immediately analyzed by the proposed method. Synthetic seawater was prepared according to ref. 35, and lake water samples were collected from Igapó Lake and treated according to our previous publication. ${ }^{34}$

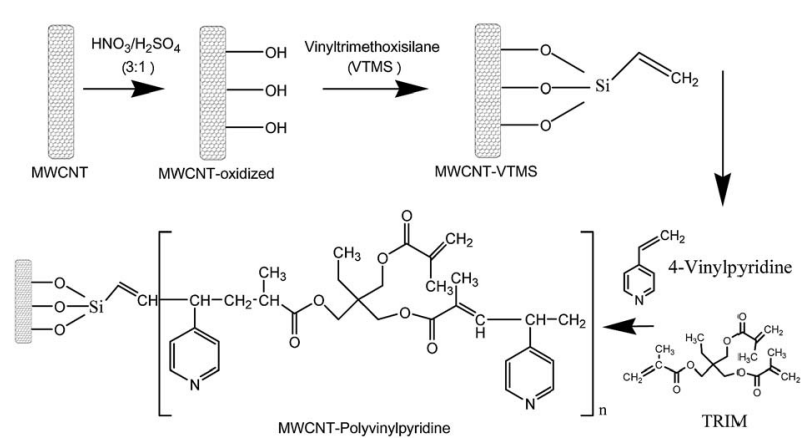

Fig. 1 Schematic representation of the synthesis of nanocomposites based on multi-walled carbon nanotubes and 4-vinylpyridine. 


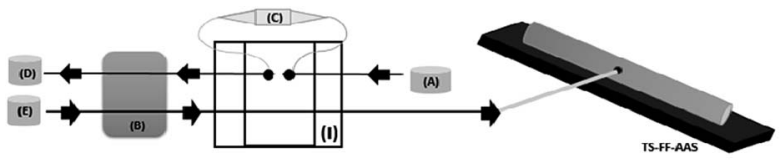

(a)

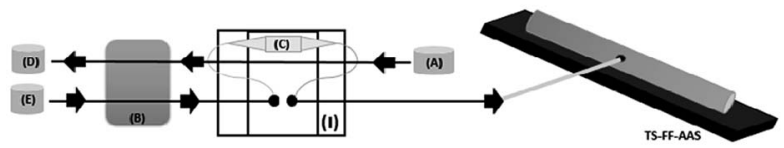

(b)

Fig. 2 Diagram of the micro-flow injection preconcentration method on-line coupled to thermospray flame furnace-AAS: preconcentration step (a) and elution step (b). A = sample, B = peristaltic pump, $C=$ minicolumn, $\mathrm{D}=$ waste, $\mathrm{E}=$ eluent.

For the digestion of solid samples, cigarette (500 mg), powdered chocolate (50\% cocoa; $700 \mathrm{mg}$ ), leaves of Ginkgo biloba $(210 \mathrm{mg})$ and a certified reference material (fish protein DORM-3; $173 \mathrm{mg}$ ) were weighted into Teflon flasks and decomposed with $10.0 \mathrm{~mL}$ of concentrated $\mathrm{HNO}_{3}$ and $4.0 \mathrm{~mL}$ $30 \%(\mathrm{v} / \mathrm{v}) \mathrm{H}_{2} \mathrm{O}_{2}$. The mixture was kept overnight followed by digestion in a closed microwave with the following sequence: heat to $80^{\circ} \mathrm{C}$ for $6 \mathrm{~min}$; maintain for $6 \mathrm{~min}$ at this temperature; heat from $80{ }^{\circ} \mathrm{C}$ to $120{ }^{\circ} \mathrm{C}$ for $7 \mathrm{~min}$; maintained for $5 \mathrm{~min}$ at $120^{\circ} \mathrm{C}$; heating to $210^{\circ} \mathrm{C}$ for $15 \mathrm{~min}$; and maintain for $20 \mathrm{~min}$ at $210{ }^{\circ} \mathrm{C} .{ }^{34}$ The digested samples were then heated on a hot plate to near dryness and cooled at room temperature. The samples were transferred to $50 \mathrm{~mL}$ volumetric flasks and then diluted to the appropriate concentration with ammoniacal buffer $(\mathrm{pH} 8.0)$.

\section{Results and discussion}

\subsection{Characterization of MWCNTs and nanocomposites}

Fig. 3a and b show the FT-IR spectra of MWCNTs (pristine, oxidized and functionalized) along with MWCNT-polyvinylpyridine and polyvinylpyridine. As can be seen from Fig. 3a, the spectra of pristine and oxidized MWCNTs are similar, except for the band at $1046 \mathrm{~cm}^{-1}$ attributed to $\delta \mathrm{CH}$. The band at $3450 \mathrm{~cm}^{-1}$ is assigned to $\mathrm{O}-\mathrm{H}$ stretching vibrations. ${ }^{11}$ The signals at 2920 and $2830 \mathrm{~cm}^{-1}$ correspond to symmetric and asymmetric $\mathrm{C}-\mathrm{H}$ stretching, the band at $1630 \mathrm{~cm}^{-1}$ can be assigned to the $\mathrm{C}=\mathrm{C}$ stretching of the carbon nanotube backbone, and the band at $1390 \mathrm{~cm}^{-1}$ may be attributed to $\mathrm{C}-\mathrm{C}$ bond stretching. ${ }^{36}$ For MWCNTs functionalized with VTMS, the bands at 3190 and $3150 \mathrm{~cm}^{-1}$, which are assigned to the $=\mathrm{CH}$ bonds, and the band at $1390 \mathrm{~cm}^{-1}$ were significantly diminished, indicating the grafting process of VTMS on the carbon nanotube backbone. Additional evidence of the grafting process is provided by the presence of the band at $1080 \mathrm{~cm}^{-1}$ in the spectrum of functionalized MWCNTs, which is characteristic of Si-O-Si stretching, and the bands at 780 and $650 \mathrm{~cm}^{-1}$, which are assigned to $\mathrm{Si}-\mathrm{O}$ stretching. ${ }^{11}$ As shown in Fig. 3b, the spectral profile of MWCNTpolyvinylpyridine is similar to that of polyvinylpyridine. The band at $1715 \mathrm{~cm}^{-1}$ can be assigned to $\mathrm{C}=\mathrm{O}$ stretching from crosslinking reagent (TRIM). ${ }^{34}$ The signal at $1630 \mathrm{~cm}^{-1}$ can be attributed to overlapping bands of $\mathrm{C}=\mathrm{C}$ stretching from vinyl groups, $\mathrm{OH}$ deformation (water) or $\mathrm{C}=\mathrm{N}$ stretching from the pyridine ring. The band at $1380 \mathrm{~cm}^{-1}$ is ascribed to $\mathrm{C}-\mathrm{N}$ stretching from the pyridine ring, which indicates the presence of the organic monomer 4-vinylpyridine in the polymeric matrix. ${ }^{37}$ Furthermore, the signal at $1460 \mathrm{~cm}^{-1}$ is ascribed to $\mathrm{C}=\mathrm{C}$ stretching from the 4 vinylpyridine ring. The intense band at $1150 \mathrm{~cm}^{-1}$ is attributed to $\mathrm{C}-\mathrm{O}$ stretching from the ester group in the TRIM structure. ${ }^{29}$

Fig. 4 shows the TGA curves of the MWCNTs (pristine, oxidized and functionalized), MWCNT-polyvinylpyridine composite and polyvinylpyridine. It is possible to observe similar thermal profile for MWCNTs with high thermal stability. A weight loss of about $13 \%$ was noted at $900{ }^{\circ} \mathrm{C}$, demonstrating that the grafting of VTMS occurred but not a polymerization reaction based on polycondensation. ${ }^{38}$ For the MWCNT-polyvinylpyridine composite and polyvinylpyridine, the observed $20 \%$ and $4 \%$ weight losses, respectively, in the $30-100{ }^{\circ} \mathrm{C}$ temperature range are attributed to moisture loss.

The TGA curve of polyvinylpyridine demonstrated that the polymer was stable to $294{ }^{\circ} \mathrm{C}$, when the polymeric chain was degraded. A significant weight loss was observed starting at $347{ }^{\circ} \mathrm{C}$ for the MWCNT-polyvinylpyridine composite; this is attributed to the degradation of the polymeric chain, indicating a protective effect of MWCNTs on the thermal stability of the polymeric chain.

The SEM images of MWCNTs are shown in Fig. 5. The images of the pristine and oxidized MWCNTs are similar and show highly tangled nanotubes. This indicates that MWCNT

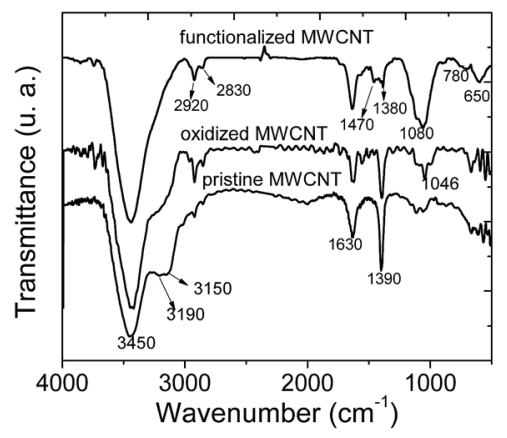

(a)

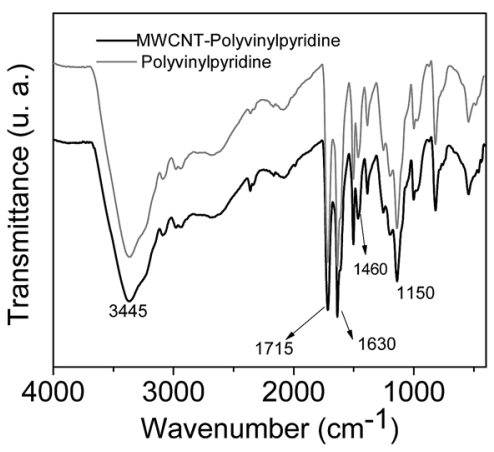

(b)

Fig. 3 FT-IR spectra of (a) MWCNTs and (b) nanocomposite (MWCNT-polyvinylpyridine) and polyvinylpyridine. 


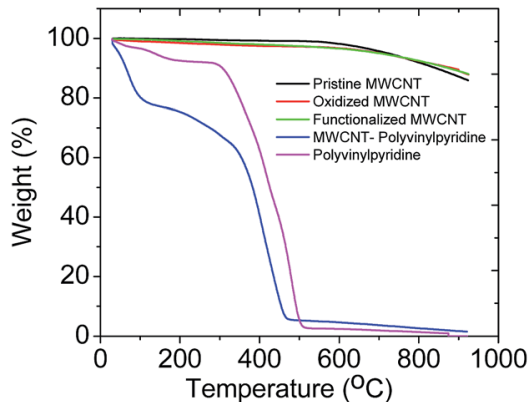

Fig. 4 Thermogravimetric curves of MWCNTs, nanocomposite (MWCNT-polyvinylpyridine) and polyvinylpyridine.

fragmentation did not occur, and that the cylindrical structures of the MWCNTs were not open-ended, corroborating the FT-IR data. This result was expected since the treatment with oxidizing agents in this study was employed primarily to create hydroxyl groups in the MWCNTs. On the other hand, the functionalization of MWCNTs with VTMS gives rise to strong aggregation attributed to grafting process.

SEM images of the MWCNT-polyvinylpyridine nanocomposite and polyvinylpyridine are shown in Fig. 6. The linkage of polyvinylpyridine on the MWCNTs can be clearly seen by the tubular shapes of the CNTs impregnated into the polyvinylpyridine network. The image of polyvinylpyridine (Fig. 6b) shows that the particles are more cohesive with a higher degree of aggregation, which is not favorable for adsorption.

The TEM images confirm the bonding of polyvinylpyridine with MWCNT, where polymer spots wrap some sections of MWCNT (Fig. 7). Additionally, it can be observed that the polymerization reaction of polyvinylpyridine also occurred in solution and in addition to surface polymerization.

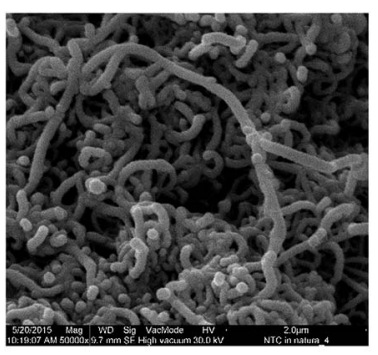

(a)

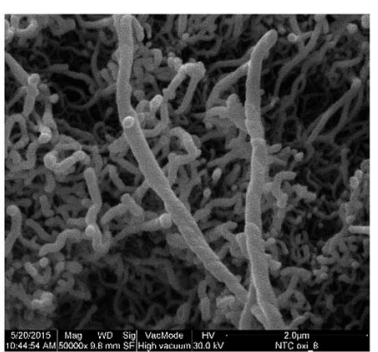

(b)

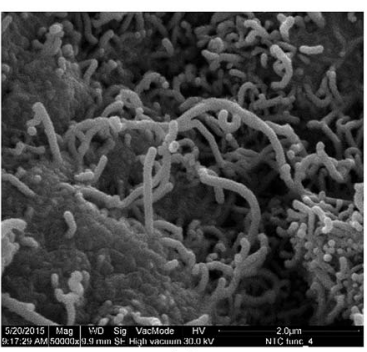

(c)

Fig. 5 SEM images of (a) pristine MWCNTs, (b) oxidized MWCNTs and (c) functionalized MWCNTs. Magnification $=50000 \times$.
Table 1 shows the textural data obtained for the materials. As expected, the surface areas of the pristine and functionalized MWCNTs are higher than those of polyvinylpyridine and the nanocomposite. The lower surface area of the nanocomposite resulted from the low pore volume, which can be explained by the penetration of MWCNTs into the polyvinylpyridine network to occupy the pores of the polymer. On the other hand, the textural data of polyvinylpyridine are similar to those of other polymers synthesized by bulk methods, ${ }^{39}$ and the particles have irregular shapes with rough surfaces.

Although polyvinylpyridine shows a higher surface area than the MWCNT-polyvinylpyridine nanocomposite, it should be noted that the nanocomposite adsorbs higher amounts of $\mathrm{Cd}$, as will be demonstrated from the sensitivity of analytical curves. This suggests that the binding sites of the polyvinylpyridine network that interact with $\mathrm{Cd}$ ions are dispersed in the nanocomposite and are much more available on the surface of material; in contrast, in polyvinylpyridine, the binding sites are most likely to be inside the polymeric network.

\subsection{Optimization of the micro-flow injection preconcentration method on-line coupled to TS-FF-AAS}

The parameters that play an important role in the preconcentration system, including sample $\mathrm{pH}$ (4.5-9.0), preconcentration flow rate (1.4-4.4 mL min $\left.{ }^{-1}\right)$, concentration and type of buffer solution were investigated.

To study the effect of $\mathrm{pH}, 26.8 \mathrm{~mL}$ of $\mathrm{Cd}$ solution at a concentration of $5.0 \mu \mathrm{g} \mathrm{L}{ }^{-1}$ were preconcentrated in the nanocomposite at a flow rate of $6.7 \mathrm{~mL} \mathrm{~min}^{-1}$. The elution step was performed with $1.0 \mathrm{~mL} \mathrm{~L}^{-1} \mathrm{HCl}$ at a flow rate of $0.6 \mathrm{~mL}$

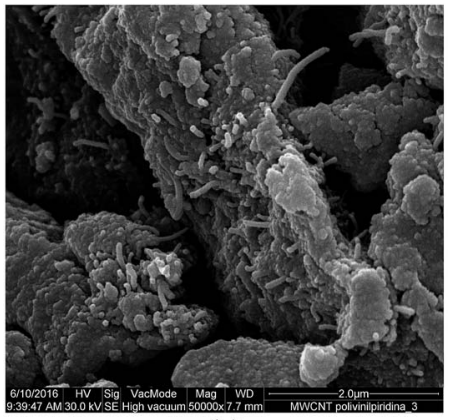

(a)

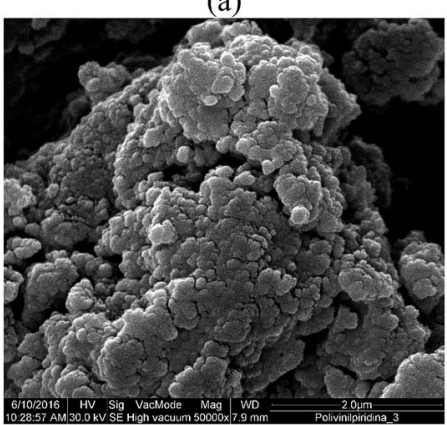

(b)

Fig. 6 SEM images of (a) MWCNT-polyvinylpyridine nanocomposites and (b) polyvinylpyridine. 


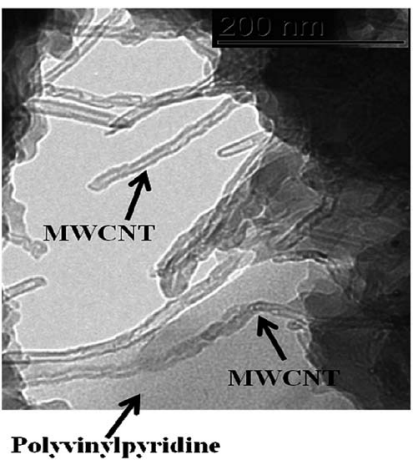

Fig. 7 TEM image of MWCNT-polyvinylpyridine nanocomposite.

$\min ^{-1}$. Fig. 8 shows that the optimal $\mathrm{pH}$ for Cd preconcentration in the nanocomposite is 8.0. According to literature data, the $\mathrm{p} K_{\mathrm{a}}$ of the monomer 4-vinylpyridine is $5.46,{ }^{40}$ while the $\mathrm{p} K_{\mathrm{a}}$ of polyvinylpyridine determined by potentiometric titration in aqueous medium is $4.0 .^{41}$ Therefore, in acidic medium, the nitrogen from the pyridine ring is protonated, leading to electrostatic repulsion with the surface of the material. On the other hand, at $\mathrm{pH}$ 9.0, the adsorption in the material decreases, most likely due to the precipitation of $\mathrm{Cd}$ ions in the hydroxide form. Thus, for further experiments, $\mathrm{pH} 8.0$ was used.

After establishing the best $\mathrm{pH}$ for Cd adsorption, the effects of different kinds of buffer solutions (ammoniacal, phosphate and Tris- $\mathrm{HCl}$ ) were evaluated.

A significant effect was noticed when phosphate was used as a buffer; this result can be rationalized on the basis of the strong interaction of phosphate salt with $\mathrm{Cd}$ ions. For ammoniacal and Tris-HCl buffers, higher analytical signals were observed, and no differences were noticed. Ammoniacal buffer was chosen over Tris-HCl due to its lower cost.

The results regarding the effect of buffer concentration (0.001-0.5 $\mathrm{mol} \mathrm{L}^{-1}$ ) showed that 0.01 and $0.1 \mathrm{~mol} \mathrm{~L}^{-1}$ provide adequate buffer capacity and the best analytical signals for $\mathrm{Cd}$ ions. For very low $\left(0.001 \mathrm{~mol} \mathrm{~L}^{-1}\right)$ and high $\left(0.5 \mathrm{~mol} \mathrm{~L}^{-1}\right)$ buffer concentrations there was a significant decrease in the analytical signal due to the reduced buffer capacity and strong interaction between ammoniacal buffer and Cd ions. Therefore, $0.01 \mathrm{~mol}$ $\mathrm{L}^{-1}$ was chosen for subsequent experiments.

The preconcentration flow rate is a very important parameter to optimize when kinetics exert an influence on adsorption; this variable is strongly related to the sensitivity and sample throughput of the method. In this experiment, $8.8 \mathrm{~mL}$ aliquots

Table 1 Textural data of materials

\begin{tabular}{|c|c|c|c|}
\hline Materials & $\begin{array}{l}\text { Surface area } \\
\left(\mathrm{m}^{2} \mathrm{~g}^{-1}\right)\end{array}$ & $\begin{array}{l}\text { Pore volume } \\
\left(\mathrm{cm}^{3} \mathrm{~g}^{-1}\right)\end{array}$ & $\begin{array}{l}\text { Average pore } \\
\text { diameter }(\mathrm{nm})\end{array}$ \\
\hline Pristine MWCNT & 203.4 & 1.3 & 26.3 \\
\hline Functionalized MWCNT & 239.5 & 2.1 & 34.2 \\
\hline $\begin{array}{l}\text { MWCNT-polyvinylpyridine } \\
\text { nanocomposite }\end{array}$ & 1.7 & $5.7 \times 10^{-3}$ & 14.2 \\
\hline Polyvinylpyridine & 56.7 & $8.0 \times 10^{-2}$ & 7.5 \\
\hline
\end{tabular}

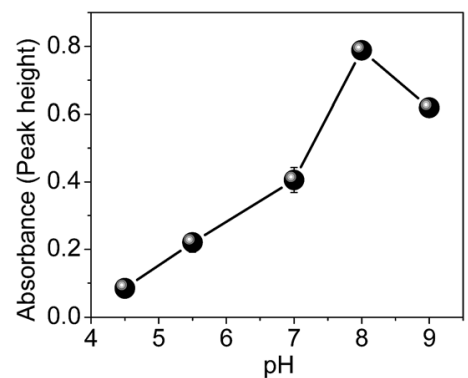

Fig. 8 Influence of $\mathrm{Cd}$ adsorption on sample $\mathrm{pH}$.

of Cd solution were preconcentrated in the nanocomposite under the optimized conditions. Lower preconcentration flow rates (1.4 and $2.8 \mathrm{~mL} \mathrm{~min}^{-1}$ ) resulted decreased analytical signal, indicating the poor accessibility of $\mathrm{Cd}$ ions due to hydrodynamic limitation. On the other hand, the preconcentration increased with the highest flow rate $\left(4.4 \mathrm{~mL} \mathrm{~min}^{-1}\right)$, which clearly also suggest fast kinetic of mass transfer of Cd toward adsorbent surface. Additionally, the higher the sample flow rate, the greater the sample throughput for the method. Thus, a flow rate of $4.4 \mathrm{~mL} \mathrm{~min}^{-1}$ was chosen as the optimum value. The elution flow rate using $1.0 \mathrm{~mol} \mathrm{~L}^{-1}$ was chosen as 0.6 $\mathrm{mL} \mathrm{min}^{-1}$ as the best value to produce a stable and continuous aerosol.

\subsection{Effect of potentially interfering ions}

To discover the degree to which the proposed method is prone to concomitant ions and macromolecules (humic acid), experiments were carried out in the presence of $\mathrm{Ca}$ (II), $\mathrm{Mg}$ (II), $\mathrm{Zn}$ (II), $\mathrm{Pb}$ (II), $\mathrm{Cu}$ (II), $\mathrm{Fe}$ (II), $\mathrm{Hg}$ (II), $\mathrm{Co}$ (II), $\mathrm{Ca}$ (II) and $\mathrm{Mg}$ (II). Binary solutions containing different ratios of analyte to interferent $[1: 1$, $1: 10,1: 50,1: 100$ and $1: 500(\mathrm{w} / \mathrm{w})]$ were subjected to the proposed method with a Cd concentration of $5.0 \mu \mathrm{g} \mathrm{L}^{-1}$. The influence of humic acid was studied at concentrations up to $5.0 \mathrm{mg} \mathrm{L}{ }^{-1}$, the normal concentration of humic substances in natural water samples, ${ }^{26}$ to simulate dissolved organic matter in natural waters. Interference was defined to be significant when a relative error of $\pm 10 \%$ in the analytic signal was observed. No interference was observed for the analyte: interferent ratios

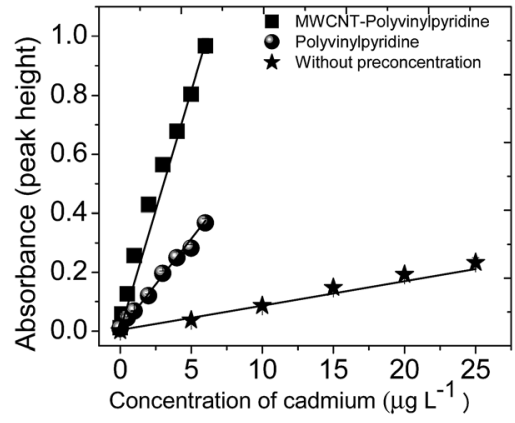

Fig. 9 Analytical curves obtained without and with preconcentration steps using the MWCNT-polyvinylpyridine nanocomposite and polyvinylpyridine as adsorbents. 
Table 2 Application and recovery of $\mathrm{Cd}($ II) in water samples

\begin{tabular}{llll}
\hline Samples & $\begin{array}{l}\text { Cd added } \\
\left(\mu \mathrm{g} \mathrm{L}^{-1}\right)\end{array}$ & $\begin{array}{l}\text { Cd found } \\
\left(\mu g \mathrm{~L}^{-1}\right)\end{array}$ & $\begin{array}{l}\text { Recovery } \\
(\%)\end{array}$ \\
\hline Tap water & 0.0 & $<\mathrm{LOD}^{a}$ & - \\
& 1.0 & $1.09 \pm 0.09$ & 109 \\
& 3.0 & $3.04 \pm 0.07$ & 101 \\
Lake water & 0.0 & $<\mathrm{LOD}$ & - \\
& 1.0 & $1.00 \pm 0.08$ & 100 \\
Mineral water (brand 1) & 3.0 & $2.74 \pm 0.09$ & 92 \\
& 0.0 & $<\mathrm{LOD}$ & - \\
Mineral water (brand 2) & 1.0 & $0.97 \pm 0.09$ & 98 \\
& 3.0 & $2.75 \pm 0.09$ & 92 \\
Synthetic seawater & 0.0 & $<\mathrm{LOD}$ & - \\
& 1.0 & $0.96 \pm 0.02$ & 97 \\
& 3.0 & $2.83 \pm 0.16$ & 94 \\
& 0.0 & $<\mathrm{LOD}$ & - \\
& 1.0 & $0.90 \pm 0.03$ & 91 \\
& 3.0 & $2.82 \pm 0.04$ & 94
\end{tabular}

${ }^{a}<\mathrm{LOD}=$ below of limit of detection. ${ }^{b}$ Results are expressed as mean value \pm standard deviation based on three replicates $(n=3)$.

investigated, indicating that Cd preconcentration can be carried free of interference in a complex matrix.

\subsection{Analytical characteristics of the proposed method}

The analytical curves obtained by TS-FF-AAS without preconcentration and with preconcentration step using the MWCNT-polyvinylpyridine nanocomposites or polyvinylpyridine are illustrated in Fig. 9 and represented by the following linear equations:

Without preconcentration:

$$
\begin{aligned}
\mathrm{Abs} & =0.0037+0.0083\left( \pm 6.13 \times 10^{-4}\right)\left[\mathrm{Cd}(\mathrm{II}), \mu \mathrm{g} \mathrm{L}^{-1}\right] ; \\
r & =0.9851,
\end{aligned}
$$

With preconcentration using polyvinylpyridine:

$$
\begin{aligned}
\mathrm{Abs} & =0.0037+0.0620\left( \pm 3.27 \times 10^{-3}\right)\left[\mathrm{Cd}(\mathrm{II}), \mu \mathrm{g} \mathrm{L}{ }^{-1}\right] \\
r & =0.9901
\end{aligned}
$$

and

With preconcentration using MWCNT-polyvinylpyridine:

$$
\begin{aligned}
\mathrm{Abs} & =0.0037+0.1621\left( \pm 3.68 \times 10^{-3}\right)\left[\mathrm{Cd}(\mathrm{II}), \mu \mathrm{g} \mathrm{L}{ }^{-1}\right] \\
r & =0.9979
\end{aligned}
$$

A comparison of the curves shows that the sensitivity of the method was sharply enhanced by the preconcentration step, particularly when the MWCNT-polyvinylpyridine nanocomposite was used as the adsorbent. The enhancement factors (EFs) were determined as the ratio of the slopes of the analytical curves built with and without the preconcentration step. The EFs obtained using the MWCNT-polyvinylpyridine nanocomposite and polyvinylpyridine were 19.5 and 7.46, respectively. These results show that the insertion of MWCNTs into the polymeric network of polyvinylpyridine improves the sensitivity for $\mathrm{Cd}$ ion determination by 2.6 times. This result can be considered satisfactory because only $40 \mathrm{mg}$ of MWCNTs were used in the synthesis, which exalts the synergic effect of MWCNTs and the polymeric matrix in the nanocomposite. The sensitivity could be increased by using a larger adsorbent mass and a higher preconcentration volume. For $8.8 \mathrm{~mL}$ of sample, the limit of detection (LOD) and limit of quantification (LOQ), determined according to IUPAC recommendations, ${ }^{42}$ were found to be 36 and $121 \mathrm{ng}$ $\mathrm{L}^{-1}$, respectively. Other important parameters in the development of solid-phase preconcentration methods, such as consumption index (CI), which is defined as the volume required to attain a unit of $\mathrm{EF}$, and the concentration efficiency (CE), defined as the EF obtained by operating the preconcentration system for $1 \mathrm{~min}$, were also calculated. ${ }^{43} \mathrm{CI}$

\begin{tabular}{|c|c|c|c|}
\hline Samples & $\mathrm{Cd}$ added $\left(\mu \mathrm{g} \mathrm{g}^{-1}\right)$ & Cd found $^{a}\left(\mu \mathrm{g} \mathrm{g}^{-1}\right)$ & Recovery (\%) \\
\hline \multirow[t]{2}{*}{ Cigarette (brand 1) } & 0.00 & $0.16 \pm 0.20 \times 10^{-2}$ & - \\
\hline & 0.15 & $0.27 \pm 0.01$ & 91 \\
\hline & 0.30 & $0.65 \pm 0.01$ & 105 \\
\hline \multirow[t]{2}{*}{ Powder chocolate } & 0.00 & $0.11 \pm 0.60 \times 10^{-2}$ & - \\
\hline & 0.10 & $0.19 \pm 0.40 \times 10^{-2}$ & 91 \\
\hline $\begin{array}{l}\text { Certified reference } \\
\text { material (DORM-3) }\end{array}$ & \multicolumn{2}{|c|}{$\begin{array}{l}\text { Certified } \\
\text { value }\left(\mu \mathrm{g} \mathrm{g}^{-1}\right)\end{array}$} & $\begin{array}{l}\text { Found value }{ }^{a} \\
\left(\mu \mathrm{g} \mathrm{g}^{-1}\right)\end{array}$ \\
\hline
\end{tabular}
and $\mathrm{CE}$ were found to be $0.40 \mathrm{~mL}$ and $9.76 \mathrm{~min}^{-1}$, respectively. The sample throughput of the proposed method was 15 $\mathrm{h}^{-1}$. The intra-day precision was evaluated by

Table 3 Application of proposed method for the determination of $\mathrm{Cd}(\Perp)$ ions in solid samples, analytical recovery from spiked samples, and analysis of a certified reference material

${ }^{a}$ Results are expressed as mean value \pm standard deviation based on three replicates $(n=3)$. 
preconcentrating $(n=10) \mathrm{Cd}$ solutions at 1.0 and $5.0 \mu \mathrm{g} \mathrm{L}^{-1}$, giving rise to relative standard deviations (RSDs) of $2.10 \%$ and $1.81 \%$, respectively. The inter-day precision for three consecutive working days using ten independent measurements yielded RSD values of $0.61 \%$ and $1.60 \%$ for the same concentrations of 1.0 and $5.0 \mu \mathrm{g} \mathrm{L}^{-1}$, respectively.

Compared with other solid-phase preconcentration methods for Cd with TS-FF-AAS determination using Amberlite XAD-4 modified with 3,4-dihydroxybenzoic acid, ${ }^{\mathbf{4}}$ fullerene modified with APDC, ${ }^{45}$ Amberlite XAD-2 modified with TAN, ${ }^{46}$ polyurethane foam modified with DDTP, ${ }^{47}$ oxidized MWCNTs ${ }^{48}$ and poly(2amino thiophenol)/MWCNT nanocomposites, ${ }^{33}$ the proposed method does not require toxic organic solvents in the flow system, presents low sample consumption, has high sample throughput, and provides a similar LOD.

\subsection{Application and accuracy in real samples}

The preconcentration method was applied to Cd determination in different kinds of water, cigarettes, a food sample (powder chocolate) and a medicinal herb (Ginkgo biloba), as shown in Tables 2 and 3. As Cd was not found in the analyzed water samples, a procedure to spike the samples with known amounts of Cd was implemented. According to the recovery values, which ranged from $91 \%$ to $109 \%$, the proposed method allows interference-free $\mathrm{Cd}$ determination, even for samples containing high salt contents.

The feasibility of applying this method for the determination of trace levels of Cd in different kinds of solid samples (cigarettes, powder chocolate, and medicinal herbs) subjected to acid digestion is assured by the high recovery values (90-105\%; Table 3$)$. As expected, Cd was found in cigarettes, ${ }^{49}$ powder chocolate ${ }^{8}$ and Gingko biloba ${ }^{7}$ samples, which represent sources of Cd uptake by human beings. The accuracy of the method was also verified by the analysis of a certified reference material DORM-3 (fish protein); the result achieved by the proposed method was statistically equal to the certified value based on a $t$-test at a confidence level of $95 \%$ (Table 3).

\section{Conclusions}

The synthesis of a nanocomposite and its application in analytical preconcentration was reported herein for the first time. The results demonstrate the great benefits of incorporating MWCNTs into the polymeric network of polyvinylpyridine as an adsorbent material for metal ions, which is of paramount importance for obtaining new analytical preconcentration methodologies. The preconcentration method on-line coupled to TS-FF-AAS has good accuracy and repeatability, low sample consumption, high sample throughput, no need for toxic organic solvents in the flow system, and broad applicability for different types of samples for the determination of trace levels of $\mathrm{Cd}$.

\section{Acknowledgements}

The authors would like to thank the Conselho Nacional de Desenvolvimento Científico e Tecnológico (CNPq) (Grant No.
481669/2013-2, 305552/2013-9, 472670/2012-3), Coordenação de Aperfeiçoamento de Pessoal de Nível Superior (CAPES) (25/ 2014), Fundação Araucária do Paraná, Secretaria da Ciência, Tecnologia e Ensino Superior do Paraná (SETI), SANEPAR, Laboratório de Espectroscopia da Central de Multiusuário da PROPPG and Instituto Nacional de Ciência e Tecnologia de Bioanalítica (INCT) (Grant No. 573672/2008-3) for their financial support and fellowships.

\section{References}

1 H.-T. Fan, J. Li., Z.-C. Li and T. Sun, Appl. Surf. Sci., 2012, 258, 3815.

2 Y. Zhai, Y. Liu, X. Chang, S. Chen and X. Huang, Anal. Chim. Acta, 2007, 593, 123.

3 Y. Liu, C. Xijun, S. Wang, Y. Guo, B. Din and S. Meng, Anal. Chim. Acta, 2004, 519, 173.

4 US EPA, National Primary Drinking Water Standards, Maximum Contaminant Level, United States Environmental Protection Agency Office of Water, 2003. http:// water.epa.gov/drink/contaminants/index.cfm\#List, accessed on July, 2015.

5 ANVISA (Brazilian Health Surveillance Agency), Consultation Paper No. 2.914, December 12, 2011, Available at (in Portuguese), http://bvsms.saude.gov.br/bvs/saudelegis/gm/ 2011/anexo/anexo_prt2914_12_12_2011.pdf, accessed January, 172016.

6 L. Yue, Biomed. Environ. Sci., 1992, 5, 53.

7 E. D. Caldas and L. L. Machado, Food Chem. Toxicol., 2004, 42, 599.

8 J. E. L. Villa, R. R. A. Peixoto and S. Cadore, J. Agric. Food Chem., 2014, 62, 8759.

9 M. Rajabi, A. Rezaie and M. Ghaedi, RSC Adv., 2015, 5, 89204.

10 F. A. C. Amorim and M. A. Bezerra, Microchim. Acta, 2007, 159, 183.

11 M. Z. Corazza, B. S. Fabrin, M. G. Segatelli and C. R. T. Tarley, J. Hazard. Mater., 2012, 243, 326.

12 M. Behbahani, A. Aliakbari, M. M. Amini, A. S. Behbahani and F. Omidi, RSC Adv., 2015, 5, 68500.

13 S. L. C. Ferreira, J. B. de Andrade, M. G. Korn, M. G. Pereira, V. A. Lemos, W. N. L. dos Santos, F. M. Rodrigues, A. S. Souza, H. S. Ferreira and E. G. P. da Silva, J. Hazard. Mater., 2007, 145, 358.

14 E. Yilmaz and M. Soylak, Environ. Monit. Assess., 2014, 189, 5461.

15 C. R. T. Tarley, N. C. Farias, G. F. Lima, F. M. de Oliveira, R. Bonfílio, D. C. Dragunski, D. N. Clausen and M. G. Segatelli, J. AOAC Int., 2014, 97, 605.

16 S. Radi, S. Tighadouini, M. Bacquet, S. Degoutin, L. Janus and Y. N. Mabkhot, RSC Adv., 2016, 6, 8250.

17 K. M. Diniz, F. A. Gorla, E. S. Ribeiro, M. B. O. Nascimento, R. J. Corrêa, C. R. T. Tarley and M. G. Segatelli, Chem. Eng. J., 2014, 239, 233.

18 H. Watanabe, K. Goto, S. Taguchi, J. W. McLaren, S. S. Berman and D. S. Russell, Anal. Chem., 1981, 53, 738.

19 M. Tuzen, K. O. Saygi and M. Soylak, J. Hazard. Mater., 2008, $152,632$. 
20 D. M. Nanicuacua, M. G. Segatelli, M. Z. Corazza and C. R. T. Tarley, Anal. Methods, 2016, 8, 2820.

21 Y. Jin-Gang, Y. Lin-Yan, Y. Hua, L. Qi, C. Xiao-Hong, J. XinYu, C. Xiao-Qing and J. Fei-Peng, Sci. Total Environ., 2015, 502, 70.

22 M. Babazadeh, R. Hosseinzadeh-Khanmiri, J. Abolhasani, E. Ghorbani-Kalhor and A. Hassanpour, RSC Adv., 2015, 5, 1988.

23 L. D. Marestoni, M. D. P. T. Sotomayor, M. G. Segatelli, L. R. Sartori and C. R. T. Tarley, Quim. Nova, 2013, 36, 1194. 24 P. Z. Ray and H. J. Shipley, RSC Adv., 2015, 5, 29885.

25 M. Khajeh, S. Laurent and K. Dastafkan, Chem. Rev., 2013, 113, 7728.

26 K. M. Diniz and C. R. T. Tarley, Microchem. J., 2015, 123, 185. 27 B. Hayati, A. Maleki, F. Najafi, H. Daraei, F. Guaribi and G. McKay, J. Mol. Liq., 2016, 224, 1032.

28 R. Kanthapazham, C. Ayyaru and D. Mahendiradas, Desalin. Water Treat., 2016, 57, 16871.

29 E. S. Moretti, F. M. Oliveira, G. L. Scheel, L. H. Dall'Antônia, D. Borsato, L. T. Kubota, M. G. Segatelli and C. R. T. Tarley, Electrochim. Acta, 2016, 212, 322.

30 J. Fu, L. Chen, J. Li and Z. Zhang, J. Mater. Chem. A, 2015, 3, 13598.

31 H. Ago, K. Petritch, M. S. P. Shaffer, A. H. Windle and R. Friend, Adv. Mater., 1999, 11, 1281.

32 M. R. Nabid, R. Sedghi, R. Hajimirza, H. A. Oskooie and M. M. Heravi, Microchim. Acta, 2011, 175, 315.

33 M. R. Nabid, R. Sedghi, A. Bagheri, M. Behbahani, M. Taghizadeh, H. A. Oskooie and M. M. Heravi, J. Hazard. Mater., 2012, 203-204, 93.

34 C. R. T. Tarley, M. Z. Corazza, F. M. Oliveira, B. F. Somera, C. C. Nascentes and M. G. Segatelli, Microchem. J., 2017, 131, 57.
35 M. Zougagh, P. C. Rudner, A. G. de Torres and J. M. C. Pavon, J. Anal. At. Spectrom., 2000, 15, 1589.

36 D. S. Ahmeda, A. J. Haiderb and M. R. Mohammad, Energy Procedia, 2013, 36, 1111.

37 D. D. Maksin, S. O. Kljajevic, M. B. Dolic, J. P. Markovic, B. M. Ekmescic, A. E. Onjia and A. Nastasovic, Hem. Ind., 2012, 66, 795.

38 E. S. Moretti, J. F. Giarola, M. Kuceki, M. C. Prete, A. C. Pereira and C. R. T. Tarley, RSC Adv., 2016, 6, 28751.

39 C. R. T. Tarley, M. Z. Corazza, B. F. Somera and M. G. Segatelli, J. Colloid Interface Sci., 2015, 450, 254.

40 Accessed on January 11, 2017. https://chemicalize.com/ \#/calculation.

41 M. Satoh, E. Yoda, T. Hayashi and J. Komiyama, Macromolecules, 1989, 22, 1808.

42 G. L. Long and J. D. Winefordner, Anal. Chem., 1983, 55, 712. 43 Z. Fang, S. Xu and S. Zhang, Anal. Chim. Acta, 1987, 200, 35. 44 V. A. Lemos, M. A. Bezerra and F. A. Amorim, J. Hazard. Mater., 2008, 15, 613.

45 M. G. Pereira, E. R. Pereira-Filho and M. A. Z. Arruda, Spectrochim. Acta, 2004, 59, 515.

46 F. A. C. Amorim and M. A. Bezerra, Microchim. Acta, 2007, 159, 183.

47 C. R. T. Tarley and M. A. Z. Arruda, Anal. Sci., 2004, 20, 961. 48 C. R. T. Tarley, A. F. Barbosa, M. G. Segatelli, E. C. Figueiredo and P. O. Luccas, J. Anal. At. Spectrom., 2006, 21, 1305.

49 C. D. Zappielo, D. M. Nanicuacua, W. N. L. dos Santos, D. L. F. da Silva, L. H. Dall'Antônia, F. M. de Oliveira, D. N. Clausen and C. R. T. Tarley, J. Braz. Chem. Soc., 2016, $27,1715$. 